\title{
SPATIOTEMPORAL MULTI-SATELLITE BIOPHYSICAL DATA ANALYSIS OF THE EFFECT OF URBANIZATION ON LAND SURFACE AND AIR TEMPERATURE IN BAGUIO CITY, PHILIPPINES
}

\author{
A. Baloloy ${ }^{1 *}$, R. R. Sta. Ana ${ }^{1}$, J. A. Cruz $^{1}$, A. Blanco ${ }^{1,2}$, N. V. Lubrica ${ }^{3}$, C. J. Valdez ${ }^{3}$, E. P. Cajucom ${ }^{4}$ \\ ${ }^{1}$ Training Center for Applied Geodesy and Photogrammetry, University of the Philippines, Diliman, Quezon City \\ 1101, Philippines - alvinbbaloloy@ gmail.com \\ ${ }^{2}$ Department of Geodetic Engineering, University of the Philippines, Diliman, Quezon City, 1101, Philippines \\ ${ }^{3}$ Research and Innovation Office, University of the Cordilleras, Governor Pack Road, Baguio City, 2600, Philippines \\ ${ }^{4}$ Climatology and Agrometeorology Division, PAGASA, Diliman, Quezon City, 1101, Philippines
}

\section{Commission IV}

KEY WORDS: Urban Heat Islands, Land Surface Temperature, Landsat, RapidEye, PlanetScope, Built-up Mapping, Google Earth Engine

\begin{abstract}
:
Urbanization can be observed through the occurrence of land-use changes as more land is being transformed and developed for urban use. One of the Philippine cities with high rate of urbanization is Baguio City, known for having a subtropical highland climate. To understand the spatiotemporal relationship between urbanization and temperature, this study aims to analyze the correlation of urban extent with land surface and air temperature in Baguio City using satellite-based built-up extents, land surface temperature (LST) maps, and weather station-recorded air temperature data. Built-up extent layers were derived from three satellite images: Landsat, RapidEye and PlanetScope. Land-use land cover (LULC) maps were generated from Landsat images using biophysical indices such as Normalized Difference Vegetation Index (NDVI) and Normalized Difference Built-up Index (NDBI); while RapidEye and PlanetScope built-up extent maps were generated by applying the visible green-based built-up index (VgNIR-BI). Mean LST values from 1988 to 2018 during the dry and wet seasons were calculated from the Landsat-retrieved surface temperature layers. The result of the study shows that the increase in the built-up extent significantly intensified the LST during the dry season which was observed in all satellite data-derived built-up maps: RapidEye+PlanetScope $(2012-2018 ; r=0.88)$, Landsat $8(2012-2018 ; r=0.63)$ and Landsat $5,7,8(1988-2018 ; \mathrm{r}=0.61)$. The main LST hotspots were detected inside the Central Business District where it expanded gradually from year 1998 (43ha) to 2011 (83ha), but have increased extensively within the years 2014 to 2019 ( 305 ha). On average, 98.5\% of the hotspots detected from 1995 to 2019 are within the equivalent built-up area.
\end{abstract}

\section{INTRODUCTION}

Urbanization refers to the general increase in population and the amount of industrialization of a settlement, mainly due to the movement of people from the rural to the urban areas. The term is widely used to describe the occurrence of land-use changes as more land becomes 'urbanized' and is developed for urban use (McGranahan and Satterthwaite, 2014). The speed of urbanization varies substantially across countries. It was observed in historical trends that the rate of urbanization is faster in less developed regions compared to the more developed regions. In the Philippines, the level of urbanization, or the proportion of urban population to the total population is 45.3 percent. This means that out of 92.3 million Filipinos in 2010, almost 42 million lived in areas classified as urban (Navarro, 2014). Based on the projection of the United Nations, the Philippine urbanization rate in 2030 and 2050 will be close to the overall rates in the Southeast Asia region.

Urbanization can have significant effects on local weather and climate. One of the most significant of these effects is called an Urban Heat Island (UHI) which can be defined as a circumstance occurring when the urban area is warmer than the rural, undeveloped surrounding (Fernando, 2013; Landsberg, 1981). In the context of urbanization, the intensity of human activities is enhanced resulting in a rapid change in the surface cover (Deng et al., 2018). The surface reflectance and roughness of different land use types are different, thus leading to differences in land surface temperature (LST). Several studies confirmed that the presence of built-up area can accelerate the effect of UHI, whereas water and green spaces can reduce the UHI intensity (Guha et al., 2018; Song et al., 2014). Aside from LST, changes in land use and cover can also raise the temperature of the local air with several degrees higher than the air temperatures of the surrounding areas (Naserikia et al., 2019).

Very limited studies were conducted to map built-up areas using higher resolution remotely-sensed imageries. These include the extraction of urban impervious surfaces from with IKONOS (Lu and Weng, 2009), SPOT5 and RapidEye (Zhang and Guindon, 2019). There are no published paper on index-based built-up mapping using PlanetScope, and very few on RapidEye; mainly because of their subscription costs and very limited spectral bands. Previous temporal built-up extent analysis in Baguio City only utilized data from the City Planning and Development Office (CPDO). A more frequent yearly data may be needed to examine the trend and status of the built-up extent, including its seasonal variations. This study aims to analyse the correlation of urban extent to land surface and air temperature in Baguio City using Landsat, RapidEye and Planet-Scope-derived builtup maps, Landsat-derived LST Maps and weather stationrecorded air temperature data. Satellite-derived biophysical indices are used as inputs including NDVI, NDBI, and VgNIRBI. Temporal hotspots expansion area and maps are also derived. 


\section{DATA AND METHODS}

Three sub-processing workflows were used in generating the main input data for the analysis and correlation of land surface and air temperature with built-up: (1) Landsat-based land-use and land-cover mapping, (2) PlanetScope and RapidEye built-up mapping and (3) LST generation (Figure 2). The outputs of the first two workflows were the multi-temporal built-up maps and the built-up expansion maps from the three satellite data. Meanwhile, the third workflow produced the multi-temporal LST layers in addition to the weather station-recorded air temperature data. Variation of hotspot locations across the generated LULC classes were then mapped using temporal hotspots detection.

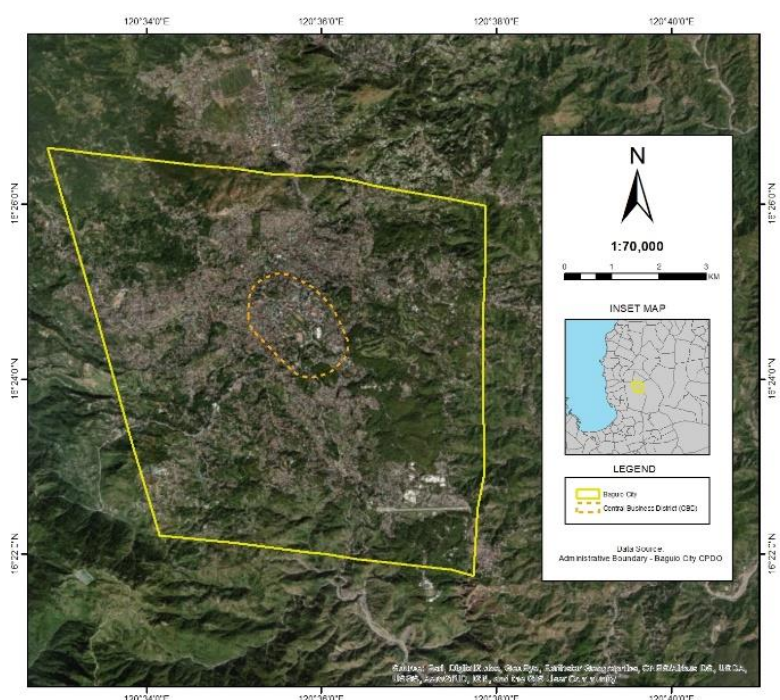

Figure 1. Map of Baguio City in northern Luzon, Philippines

\subsection{Study Site}

Baguio City is located in northern Luzon Island, Philippines, approximately $250 \mathrm{~km}$ north of Manila. It is geographically located within the province of Benguet and serves as the regional

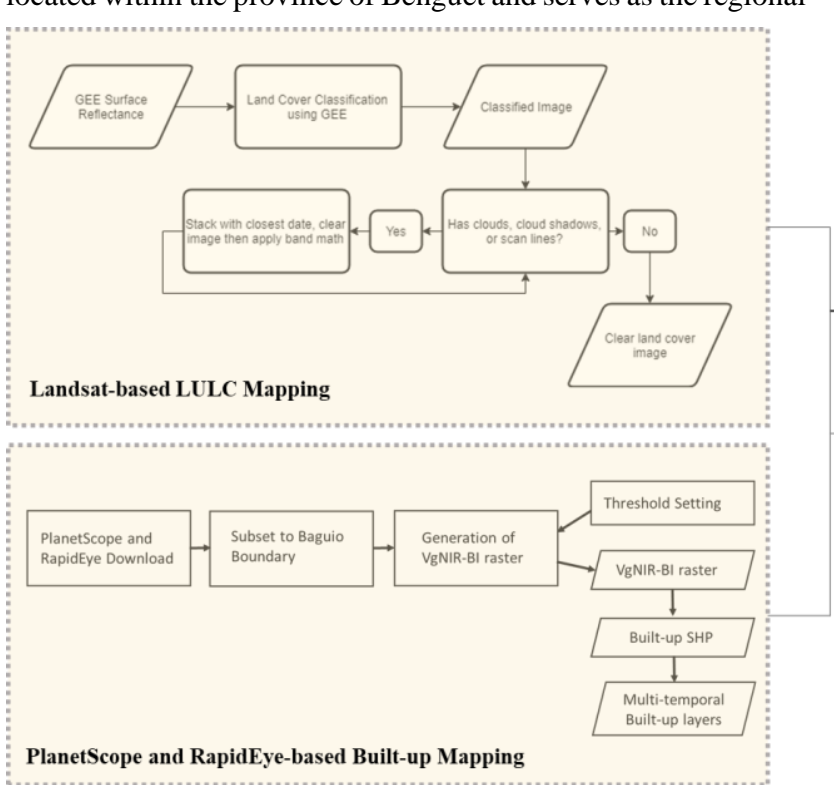

center of the Cordillera Administrative Region (CAR, Figure 1). Baguio is considered as the country's "Summer Capital" with an annual average temperature of $19.7^{\circ} \mathrm{C}$, generally lower by 8 $10^{\circ} \mathrm{C}$ than those of the low land areas. The city has an altitude of 1,417 meters above sea level.

\subsection{Landsat-based Land-use Land-cover Mapping}

Land use and land cover classification images were generated using Landsat 5, 7, and 8 surface reflectance images of the study area. One classification image was created per year from 1987 to 2019. Each image is made by first applying thresholding to all available images from a single year using Google Earth Engine. This classifies the pixels in each image into 6 classes (vegetation, built-up, bare soil, water, clouds, and cloud shadows). The thresholds used in the classification can be seen in NDVI was used as the threshold for vegetation, and NDBI and NDVI for built-up and bare soil.

\begin{tabular}{ccc}
\hline Class & NDVI & NDBI - NDVI \\
\hline Vegetation & $>=0.5$ & \\
Built-up & $<0.5$ & $>=-0.5$ \\
Bare Soil & $<0.5$ & $<-0.5$ \\
\hline
\end{tabular}

Table 1. Classification thresholds use in generating the multitemporal Landsat-based Land-use Land-cover map of Baguio

The threshold values are specific for the study area and were obtained through manual visual inspection of selected images. For water, clouds, and cloud shadows, the Landsat pixel_qa band was used. Once image classification is done, the April image of the year is checked for cloud and cloud shadow pixels. Landsat 7 images were also checked for noData pixels due to scan line errors. If these are found in the image, they are replaced with pixels from the temporally nearest image within the same year. This is then repeated until either there are no more clouds, cloud shadow, or noData pixels left in the image or there are no more available images within the same year. This was applied to each year to produce yearly land cover composites of the study area.

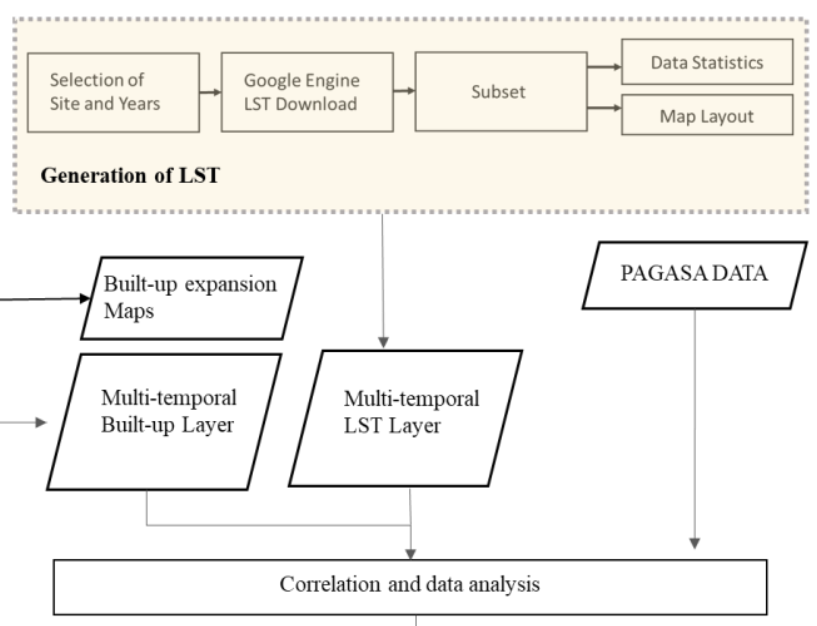

Detection of temporal variation of hotspot locations across the generated LULC classes

Figure 2. General research workflow divided into urban extent mapping, land and air temperature generation, and data analysis 


\subsection{PlanetScope and RapidEye Built-up Mapping}

Aside from Landsat, two higher resolution satellite data were utilized to generate built-up maps for Baguio: PlanetScope and RapidEye with $3 \mathrm{~m}$ and $5 \mathrm{~m}$ spatial resolutions, respectively. Separate yearly maps were generated for PlanetScope and RapidEye, each with varying levels of accuracy. However, both data were combined for the built-up and temperature correlation and analysis due to limited available clear images. The earliest clear PlanetScope and RapidEye images for the study site are obtained in 2017 and 2012, respectively (Table 2).

\begin{tabular}{ll}
\hline PlanetScope Images & RapidEye Images \\
\hline April 24, 2019 & January 20, 2018 \\
April 28, 2018 & February 02, 2015 \\
April 06, 2017 & February 07, 2012 \\
\hline
\end{tabular}

Table 2. Downloaded PlanetScope and RapidEye data used for generating the higher resolution index-based built-up maps

\subsubsection{Spectral Built-up Index}

The derivation of built-up maps from Landsat was discussed in section 2.2. A different methodology was applied to PlanetScope and RapidEye due to the limitation of its spectral bands. An index-based mapping which is applicable to both satellites were utilized using the visible green based built-up index (VgNIR-BI) proposed by Estoque and Murayama (2015).

$$
\text { VgNIR-BI }=\frac{\rho_{\text {Green }}-\rho_{\text {NIR }}}{\rho_{\text {Green }}+\rho_{\text {NIR }}}
$$

where $\rho$ Green and $\rho N I R$ refer to the atmospherically corrected surface reflectance values of band 3 and band 5 of the Landsat8 OLI/TIRS image, respectively. The equivalent bands for PlanetScope are stated in the table below (Table 3).

\begin{tabular}{lll}
\hline Satellite & Green Band & NIR Band \\
\hline Landsat- 8 & B3 $(533-590 \mathrm{~nm})$ & B5 $(851-879 \mathrm{~nm})$ \\
PlanetScope & B2 $(500-590 \mathrm{~nm})$ & B4 $(780-860 \mathrm{~nm})$ \\
RapidEye & B2 $(520-590 \mathrm{~nm})$ & B5 $(760-850 \mathrm{~nm})$ \\
\hline
\end{tabular}

Table 3. Satellite bands utilized in generating the RapidEye and PlanetScope-based VgNIR-BI indices

\subsubsection{Optimal Thresholding}

Index-based mapping requires the identification of optimal threshold that can best separate two or more classes. In the case of VgNIR-BI, the threshold must separate the (1) built-up class from the (2) non-built-up and water classes. Previous studies have utilized the use of Otsu thresholding method (Otsu, 1979) especially for VgNIR-BI where good results were obtained (Estoque and Murayama, 2015; Zhang et al., 2017). Initial results of Otsu-thresholding with RapidEye and PlanetScope data were compared with visible RGB images and adjustment of values were applied. The final threshold is needed before extracting the built-up shapefile for areal extent computation.

\subsection{Map Accuracy Assessment}

The accuracies of the built-up maps generated from Landsat, PlanetScope and RapidEye were computed using the field data collected from the Central Business District, Baguio City. Eighty (80) randomized validation points, composed of 66 built-up points and 14 non-built-up points, were collected. These nonbuilt-up points were collected within vegetation, bare soil and water surface. Present and previous Google Earth images were used to check sample expanded areas as seen in the built-up expansion maps.

\subsection{Land Surface Temperature (LST) Retrieval}

To generate the land surface temperature for each year, the study adopted the LST retrieval method that was developed by Jeevalakshmi et al. (2017) using Landsat data. The calculation of LST was composed of six main steps: (1) conversion of digital number (DN) values to at-sensor radiance, (2) conversion of thermal band data to brightness temperature, (3) calculation of the normalized difference vegetation index (NDVI) to differentiate various land cover types within the image, (4) calculation of the proportional vegetation from NDVI to estimate the area of each land cover type, (5) calculation of land surface emissivity (LSE) to scale the black body radiance across different surfaces, and (6) calculation of LST using the formula:

$$
T_{S}=\frac{B T}{\left\{1+\left[\left(\frac{\lambda B T}{\rho}\right) \ln \varepsilon_{\lambda}\right]\right\}}
$$

where $\quad T_{S}=$ land surface temperature $\left({ }^{\circ} \mathrm{C}\right)$

$B T=$ at-sensor brightness temperature $\left({ }^{\circ} \mathrm{C}\right)$

$\lambda=$ average wavelength of thermal band

$\varepsilon_{\lambda}=$ land surface emissivity

$$
\rho=1.438 \times 10^{-2} \mathrm{mK}
$$

\begin{tabular}{cccc}
\hline Acquisition Date & $\begin{array}{c}\text { Landsat } \\
\text { Satellite }\end{array}$ & Acquisition Date & $\begin{array}{c}\text { Landsat } \\
\text { Satellite }\end{array}$ \\
\hline April 10, 2019 & L08 & February 17, 2003 & L07 \\
March 6, 2018 & L08 & April 3, 2002 & L07 \\
March 10, 2017 & L08 & March 23, 2001 & L05 \\
February 13, 2016 & L08 & March 11, 2000 & L05 \\
March 5, 2015 & L08 & March 18, 1999 & L05 \\
February 7, 2014 & L08 & April 7, 1998 & L05 \\
February 3, 2013 & L07 & April 20, 1997 & L05 \\
March 4, 2012 & L07 & March 25, 1996 & L05 \\
March 10, 2011 & L05 & March 14, 1995 & L05 \\
January 27, 2010 & L05 & February 7, 1994 & L05 \\
January 15, 2009 & L05 & February 13,1993 & L05 \\
February 20,2007 & L05 & February 27, 1992 & L05 \\
April 6, 2006 & L05 & April 10, 1990 & L05 \\
February 14, 2005 & L05 & February 18, 1989 & L05 \\
March 15, 2004 & L05 & March 3, 1988 & L05 \\
\hline
\end{tabular}

Table 4. Selected Image Acquisition Date per Year

The LST retrieval methodology was implemented using Google Earth Engine, a cloud computing platform for processing satellite imagery such as Landsat. The developed GUI allows the users to choose the Landsat satellite sensor (Landsat TM, ETM, or OLI/TIRS), and the image acquisition date. One cloud-free satellite image within the hot dry season of Baguio City (February to April) was selected for each year from 1988 to 2019 except for 1991 and 2008 wherein no images were downloaded due to unavailability. The generated LST layers were clipped 
using the administrative boundary shapefile of Baguio City and the average surface temperature for each image was calculated. For the LST values that were regressed against AT and built-up, seasonal mean LST for dry and wet season were downloaded from Climate Engine (http://www.climateengine.org)

\subsection{Air Temperature (AT) Data}

Daily minimum and maximum temperature dataset (1990 to present) were collected from the Philippine Atmospheric, Geophysical and Astronomical Services Administration (PAGASA) station in Baguio City.

\subsection{Built-up and Temperature Correlation and Analysis}

Multi-temporal dry and wet season LST were regressed with the multi-temporal dry and wet season air temperature (AT). Pearson correlation between each season (dry versus wet) for each temperature type was also computed. The multi-temporal LST and AT were then regressed with the computed built-up area from Landsat, RapidEye and PlanetScope. The correlation coefficient (r) were computed for three regression groups based on the built-up inputs: (1) temperature versus RapidEye+PlanetScope built-up extent, 2012-2018, (2) temperature versus Landsat 8 built-up extent, 2012-2018 and (3) temperature versus extended Landsat built-up, 1990-2018.

\subsection{Temporal LST Hotspot Detection}

Hotspot detection was applied to the Landsat LST images to determine the trend of the prevalence of intra-UHIs in the study area over time. Landsat images from 1988 to 2019 were used in the analysis. The image with least cloud cover was selected for each year. Years with no clear images were excluded from the analysis. The pixel values in each image were then reclassified using ArcGIS into 7 classes with natural breaks as thresholds. Each class was assigned a value of -3 to 3 from lowest to highest. The images were then separated into 6 groups (Table 5) with each group composed of 4 consecutive clear images.

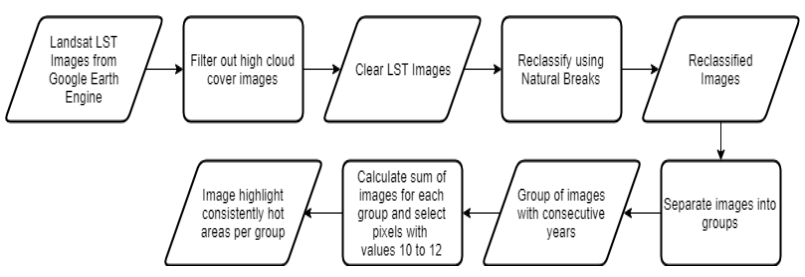

Figure 3. Hotspot detection workflow applied to the generated Baguio City LST layers from Landsat (1998 to 2019)

\begin{tabular}{cc}
\hline Group & Years Included \\
\hline 1 & $1989,1990,1992,1993$ \\
2 & $1995,1996,1997,1998$ \\
3 & $1999,2000,2001,2002$ \\
4 & $2003,2004,2005,2006$ \\
5 & $2007,2009,2010,2011$ \\
6 & $2014,2016,2018,2019$ \\
\hline
\end{tabular}

Table 5. Landsat yearly images per group

The time difference between the years of images was taken into account in the selection of groupings. The sum of the reclassified images in each group were then calculated and pixels with a value of 10 to 12 were determined. Since there are 4 images in each group, a maximum value of 12 can be obtained. The range 10 - 12 was selected as this corresponds to pixels which are consistently in the upper $50 \%$ pixel value in each year. These images were then compared with land cover images of the same year to determine the correlation between built-up extents and surface temperature.

\section{RESULTS AND DISCUSSION}

\subsection{Landsat-based Land-use Land-cover Mapping}

The land cover classification method used was able to effectively classify vegetation in the study area but had difficulty separating built-up from bare soil. However, it was observed through visual inspection that bare soil in the area is sparse and so this accuracy is acceptable. Creating yearly composites instead of using single-date images was able to minimize cloud, cloud shadow, and noData pixels in the images. This was especially effective in solving the scan line errors in Landsat 7 images (Figure 4). The overall trend of built-up area is increasing, but relatively higher values occurred in between the oldest (1980) and latest images (2019). Four higher built-up areas are recorded during the years 1998 (2,863 ha), 2002 (2,834 ha), 2010 (2694 ha) and 2019 (2286 ha). This growth and sprawl of built-up structures in Baguio City were attributed to the continued increase in population, physical constraints of topography and its limited land area (Gonzales, 2016). Meanwhile, the lowest total areas were recorded in earlier years: 1992 (724 ha) and 1993 (635 ha). The urban extent generated in this study are lower than the available Baguio CPDO data (2002, 2010 and 2013).

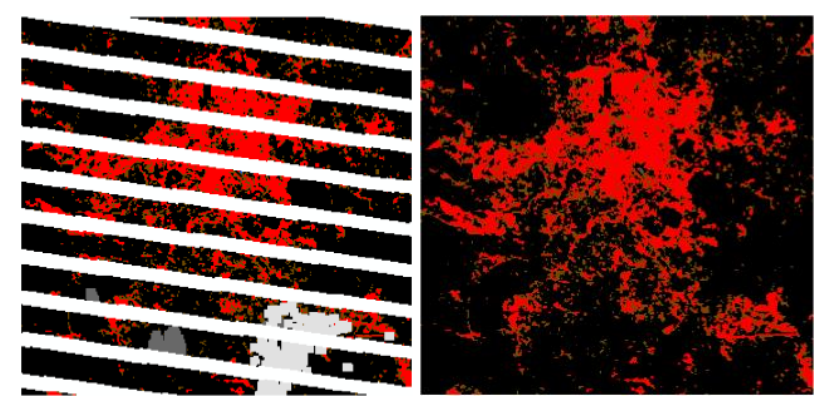

Figure 4. Landsat 7 April 2008 image showing scan errors (left) and 2008 yearly composite image (right) taken in Baguio City

Negative correlation was observed between built-up and vegetation, similar to previous studies (Guha et al, 2018, Malik et al., 2019). The highest vegetation area (4,883 ha) and lowest built-up extent (1,094 ha) computed using Landsat- 8 data were recorded in 2013; while the lowest vegetation area (3,544 ha) and highest built-up extent were recorded in year 2019.

\subsection{PlanetScope and RapidEye Built-up Mapping}

Three built-up maps were generated for PlanetScope and three for RapidEye (Figure 5). A fixed threshold value of 0 was used for all images; this was found to delineate roads better that the Otsu thresholding results. For RapidEye, an increasing area extent were computed from 2012 (789.23 ha), 2015 (950.36 ha) to 2018 (961.54 ha). Similar trend was observed with PlanetScope, from year 2017 (903.61 ha), 2018 (990.20) to 2019 $(1,247.88$ ha). The built-up expansion maps were generated by displaying the newest over the oldest image per satellite data as 

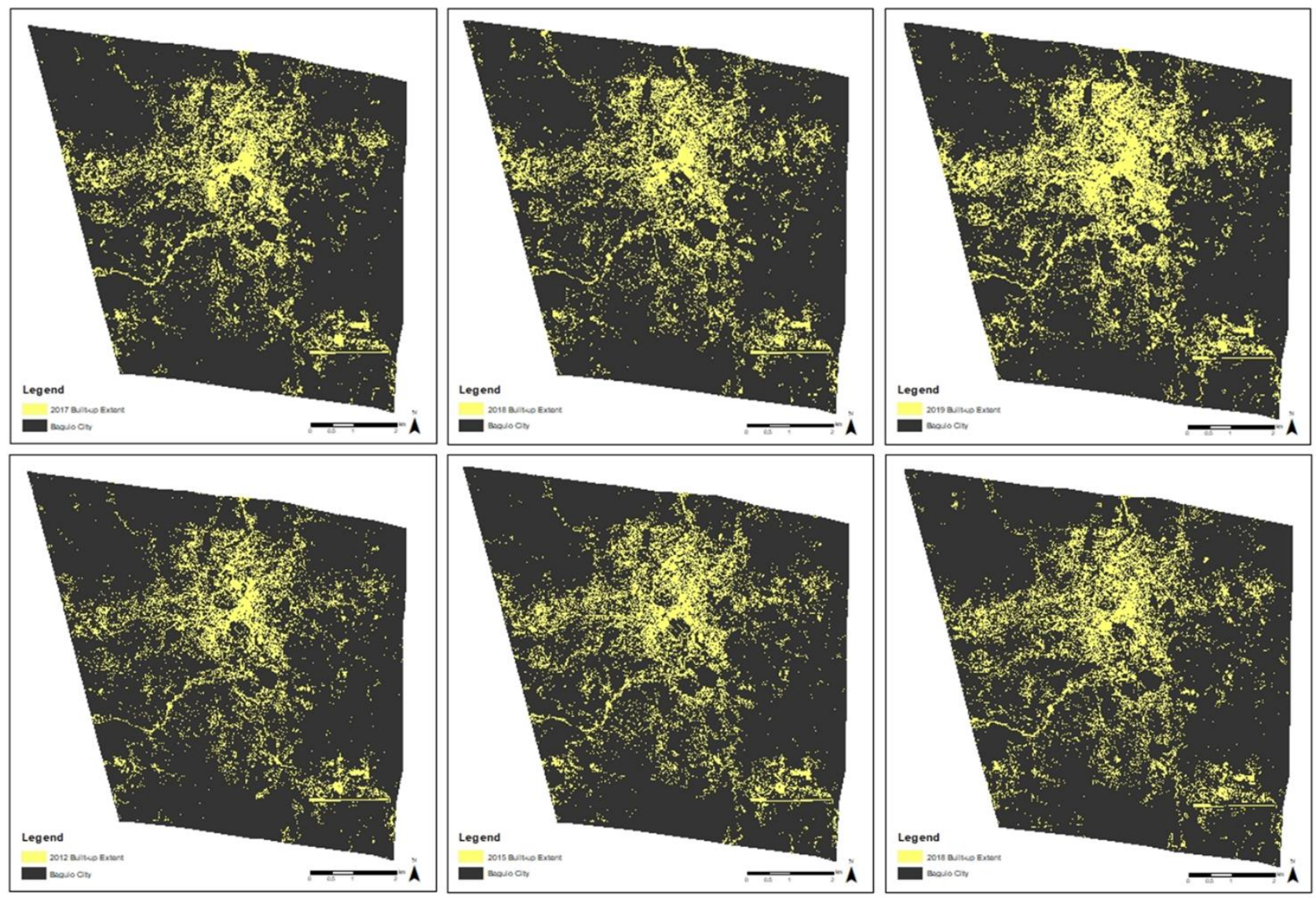

Figure 5. Yearly PlanetScope (2017, 2018 and 2019, top) and RapidEye (2012, 2015 and 2018) built-up maps of Baguio City generated using the visible green based built-up index (VgNIR-BI) derived from the green and NIR bands of the two satellite data
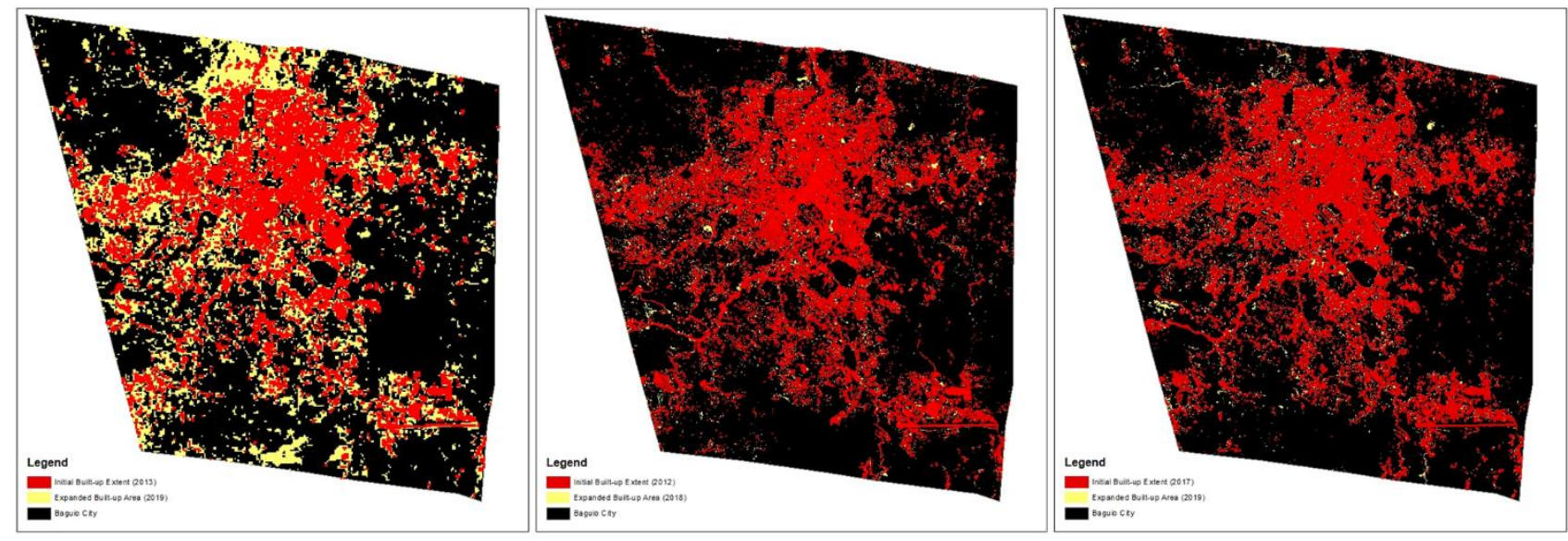

Figure 6. Side to side comparison of the built-up expansion maps generated for Landsat (right), RapidEye and PlanetScope (right)

seen in Figure 6. The increase in total built-up area is 172 ha for RapidEye (2012-2018) and 344 ha for PlanetScope (2017-2019) which are both relatively lower than the built-up increase computed from Landsat-8 (1,300 ha for 2013-2019). Most of the expanded areas in PlanetScope are also detected in RapidEye.

\subsubsection{Map Accuracy Assessment}

The highest map accuracy was obtained with PlanetScope (95\%), the satellite data with the highest spatial resolution (3 m); followed by RapidEye (81\%, $5 \mathrm{~m})$, and Landsat $(76 \%, 30 \mathrm{~m})$.
Due to low spatial resolution of Landsat data, validation points within small buildings and roads mistakenly falls within the neighbouring Landsat pixels of non-built up cover. PlanetScope generated high accuracy results for both built-up (93.9\%) and non-built-up (100\%). No previous built-up mapping studies were conducted using PlanetScope. The expanded built-up areas obtained from PlanetScope and RapidEye maps were correctly detected as newly built structures as seen in Google Earth imagery. Most of these are extensions of old residential and commercial structures, but some are converted from totally different land use and cover such as vegetation and bare lands. 


\subsection{Land Surface and Air Temperature}

The mean annual land surface temperature of Baguio City has an increasing trend (Figure 7). The years with the highest LST were observed to be in the past year 2000s: $2009\left(26.6^{\circ} \mathrm{C}\right), 2015(26.8$ $\left.{ }^{\circ} \mathrm{C}\right)$, and $2018\left(27.5^{\circ} \mathrm{C}\right)$. On the other hand, the lowest average LST were observed on earlier years: $1990\left(23.2^{\circ} \mathrm{C}\right), 1991(22.9$ $\left.{ }^{\circ} \mathrm{C}\right), 1993\left(23{ }^{\circ} \mathrm{C}\right)$ and $1998\left(23{ }^{\circ} \mathrm{C}\right)$. From an annual average LST of $23.2^{\circ} \mathrm{C}$ in 1990 , the mean LST of Baguio City increased to $27.5{ }^{\circ} \mathrm{C}$ in 2018 , with an increment of $0.11^{\circ} \mathrm{C}$ per year. Variations in surface temperature between these years is due to the changes in land cover types within the city since land surface temperature is heavily dependent on the surface properties of an area. As seen in the result of Landsat-based and-use land-cover mapping discussed earlier, an inverse trend was observed between the vegetation and built-up extent in Baguio City.

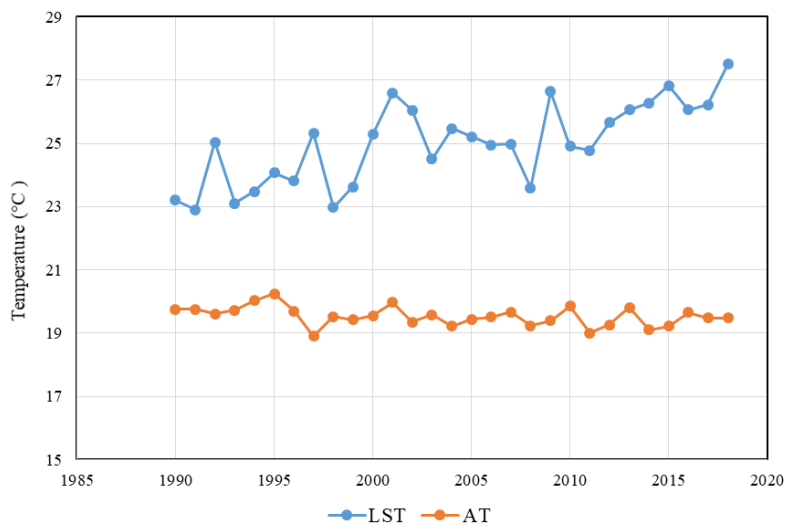

Figure 7. Mean Annual LST and AT of Baguio City from 1990 to 2018. Increasing LST was observed during the study period.

Unlike LST, very little variations were observed in the annual mean air temperature in Baguio, with values ranging from 19.1 ${ }^{\circ} \mathrm{C}$ to $20.2{ }^{\circ} \mathrm{C}$. From an annual average AT of $19.8^{\circ} \mathrm{C}$ in 1990 , the mean LST of Baguio City declined to $19.5^{\circ} \mathrm{C}$ in 2018 , with a negligible difference of only $0.3^{\circ} \mathrm{C}$.

\subsubsection{Seasonal and Temperature Type Correlation}

\begin{tabular}{ccc}
\hline \multicolumn{1}{c}{ Parameter } & $\mathrm{r}$ & $\mathrm{R}^{2}$ \\
\hline Dry Season AT and LST & 0.19 & 0.04 \\
Wet Season AT and LST & 0.26 & 0.07 \\
Dry and Wet Season LST & 0.44 & 0.2 \\
Dry and Wet Season AT & 0.33 & 0.11 \\
\hline
\end{tabular}

Table 6. Correlation results of seasonal (dry and wet season) and temperature types (LST and AT) in Baguio City

The study found no strong correlation between the temperature types (LST versus AT) within each season; and between dry and wet season for each temperature type (Table 6). The first observation shows that LST is not a strong driving force in either increasing or decreasing air temperature. The AT of Baguio City might be more affected by its altitude, which is on average, $8^{\circ} \mathrm{C}$ lower than the temperature in the lowland areas (Estoque and Murayama, 2015). Furthermore, the AT was measured from a static weather station of PAGASA located within the CBD, thus providing measure of ambient AT within limited area. The LST data generated from Landsat was collected at around 10AM while the AT used in the study was the daily mean temperature.

\subsection{Built-up and Temperature Correlation and Analysis}

Results of the Pearson correlation analysis between different temperature and built-up extent data show that dry season LST has a strong positive relationship with the generated built-up areas (Table 7, Figure 8). This correlation was observed in all satellite data: RapidEye+PlanetScope images $(r=0.88)$, Landsat-8 $(r=0.63)$ and Landsat 5,7,8 $(r=0.61$, Tables 7-9). This linear relationship between built-up and LST during the dry season was previously observed using MODIS LST data (Morabito et al., 2016). In the long term (1990-2018) Landsat data, only the dry season LST generated a strong positive correlation with the built-up extent (Table 9).

The current study is among the few researches to relate LST variations with high resolution built-up maps. Higher correlation value was obtained when the built-up extent was mapped using RapidEye and PlanetScope as compared to Landsat results, which means that there is a need to accurately delineate the impervious areas within the city to depict concise relationships between urbanization and LST.

\begin{tabular}{cccccc}
\hline Season & Temperature & $\begin{array}{c}\text { Built-Up } \\
\text { Extent }\end{array}$ & $\mathrm{r}$ & $\mathrm{R}^{2}$ & $\begin{array}{c}\mathrm{p} \\
\text { value }\end{array}$ \\
\hline Dry & LST & RapidEye & 0.88 & 0.78 & 0.005 \\
Dry & AT & + & 0.13 & 0.02 & 0.001 \\
Wet & LST & $\begin{array}{c}\text { Planet- } \\
\text { Scope }\end{array}$ & 0.26 & 0.07 & 0.001 \\
Wet & AT & Dcol & 0.42 & 0.18 & 0.001 \\
\hline
\end{tabular}

Table 7. Correlation between temperature and built-up extent derived from RapidEye/PlanetScope images (2012-2018)

\begin{tabular}{cccccc}
\hline Season & Temperature & $\begin{array}{c}\text { Built-Up } \\
\text { Extent }\end{array}$ & $\mathrm{r}$ & $\mathrm{R}^{2}$ & $\begin{array}{c}\mathrm{p} \\
\text { value }\end{array}$ \\
\hline Dry & LST & & 0.63 & 0.39 & 0.001 \\
Dry & AT & Landsat-8 & 0.62 & 0.38 & 0.001 \\
Wet & LST & images & 0.07 & 0.05 & 0.001 \\
Wet & AT & & 0.37 & 0.14 & 0.001 \\
\hline
\end{tabular}

Table 8. Correlation between temperature and built-up extent derived from Landsat 8 images (2012-2018)

\begin{tabular}{cccccc}
\hline Season & Temperature & $\begin{array}{c}\text { Built-Up } \\
\text { Extent }\end{array}$ & $\mathrm{r}$ & $\mathrm{R}^{2}$ & $\begin{array}{c}\mathrm{p} \\
\text { value }\end{array}$ \\
\hline Dry & LST & & 0.61 & 0.37 & 0.001 \\
Dry & AT & $\begin{array}{c}\text { Landsat } \\
5,7,8\end{array}$ & 0.18 & 0.03 & 0.001 \\
Wet & LST & images & 0.31 & 0.1 & 0.001 \\
Wet & AT & & 0.04 & 0.001 & 0.001 \\
\hline
\end{tabular}

Table 9. Correlation between temperature and built-up extent derived from Landsat 5,7,8 images (1990-2018)

The correlation between AT and built-up during the wet season is better than LST both in the recent short term (2012-2018) RapidEye/PlanetScope images (Table 7) and short term Landsat data (Table 8 ). Very weak to moderate correlations between built-up and LST layers were obtained during this season. This 
indicated that meteorological factors such as amount of precipitation should also be considered in the analysis. Likewise, generally low correlations were calculated between built-up data and air temperature. Only the dry season atmospheric temperature generated good correlation with built-up extent (Landsat; $r=0.62$ ). The result demonstrated that the variability of atmospheric temperature is not solely dependent on land cover types and surface properties. The moisture deficits alone during the dry seasons can already increase the occurrence of high air temperature extremes (Hirschi, et al, 2010; Vautardet al., 2007). Locally, air temperature is also affected by altitude.

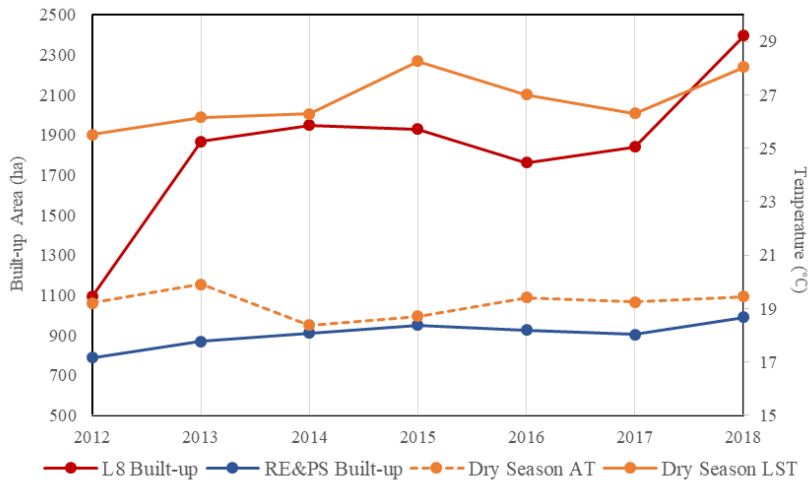

Figure 8. Correlation between built-up extent and dry season Land surface and air temperature in Baguio City from 2012-2018

\subsection{Temporal LST Hotspot Detection}

Images highlighting consistently hot locations in the study area throughout the study period were generated using hotspot analysis. Four clear consecutive years were grouped (Table 10) and areas with consistent high LST values were detected for each group (Figure 9). It was observed that the total hotspot area has an increasing trend over time with an exception between group 2 and 3 where the hotspot area reduced. Inconsistencies in the areal extent can arise due to the limitation of using Landsat data for built-up mapping, as seen in the accuracy assessment results.

\begin{tabular}{c|c|c}
\hline Group & Years included & Hotspots area (ha) \\
\hline 1 & $1989,1990,1992,1993$ & 43.37 \\
2 & $1995,1996,1997,1998$ & 105.29 \\
3 & $1999,2000,2001,2002$ & 72.91 \\
4 & $2003,2004,2005,2006$ & 92.75 \\
5 & $2007,2009,2010,2011$ & 82.82 \\
6 & $2014,2016,2018,2019$ & 305.82 \\
\hline
\end{tabular}

Table 10. Size in hectares of hotspots areas per group

The main LST hotspots were detected inside the Central Business District (Figure 9) where it expanded gradually from 43ha in year 1998 to 83ha in 2011, but have increased extensively within the years 2014 to 2019 (Group 6; 305 ha). Within the years under group 6, a combination of newly built commercial and residential houses and expansion of existing structures was observed from the higher resolution maps. From 1989 to 1993, hotspots were located in southern Baguio. It then shifted to the Central Business District starting from year 1995 to present. The increase in hotspots corresponded with an increase in built-up extent $(r=0.44)$.
On average, $98.5 \%$ of the hotspots detected from 1995 to 2019 are within the equivalent built-up area (Figure 10). This linear trend indicated that the continuously increasing built-up areas in Baguio City will likely result to an increasing LST hotspot areas expanding from the CBD.
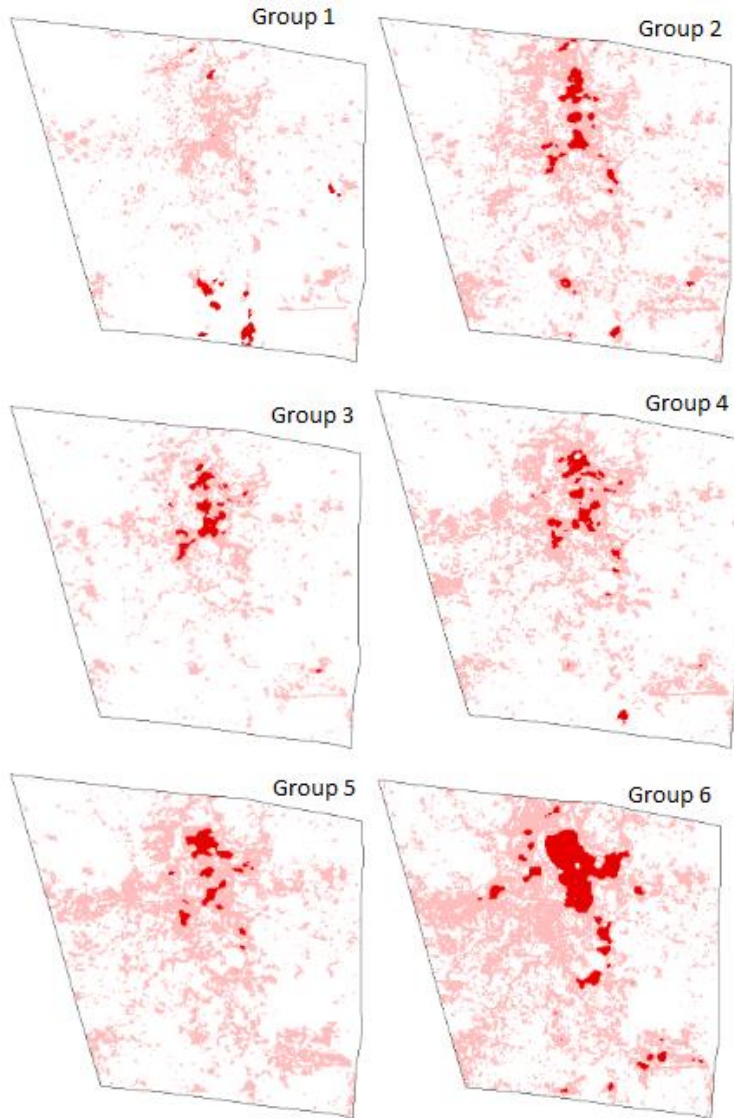

Figure 9. Hotspots per input group (highlighted in red) overlaid to the equivalent Landsat-derived built-up maps (in light red)
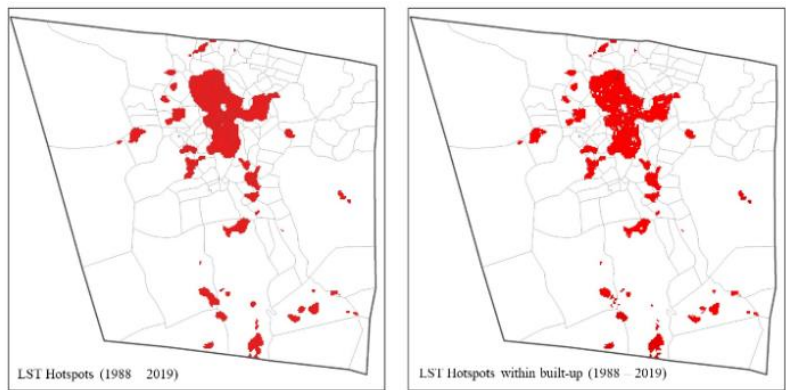

Figure 10. LST hotspots (left) and the LST hotspots that occur within the built-up areas (right) in Baguio City from 1998-2019

\section{CONCLUSION}

The study assessed the correlation of urban extent to land surface and air temperature in Baguio City using Landsat, RapidEye and Planet-Scope-derived built-up maps; Landsatderived LST Maps and PAGASA station-recorded air temperature data. Biophysical indices were used as inputs in mapping the built-up extent: NDBI and NDVI for Landsat and VgNIR-BI for PlanetScope and RapidEye. The accuracy of the output maps were seen to be affected by the spatial resolution of the satellite data, where PlanetScope generated the highest accuracy of $95 \%$, followed by RapidEye ( $81 \%$ ). The limitation 
of Landsat in built-up mapping include overestimation of narrow roads and small buildings, and misclassification of solitary builtup structures surrounded by bigger non-built-up structures. The strong linear relationship between built-up extent and LST data were observed in Baguio City during the dry season only. With the absence of moisture and cold air temperature extremes in this season, the total measured LST was strongly dependent on the total area of built-up structures. It was suggested that other local factors might affect LST and AT during the wet season other than the built-up extent. The LST and AT alone generated weak correlation which is different from the results of other studies conducted in low and highland areas. This means that the LSTAT interaction in the study site is more complex and can be further investigated by incorporating other physical factors such as altitude, precipitation, humidity, and climatic divergence. Meanwhile, the LST hotspots were mainly detected inside the Central Business District where major residential and commercial structures were built. The study found that an initial gradual increase in hotspots areas took place in earlier years (before 2010) and it was just recently (2014-2019) that the hotspots areas have expanded rapidly and extensively. The detected hotspots occurred on the growth nodes previously determined by the CPDO. This study, however, have illustrated both the spatial and temporal growth of the hotspots area as affected by the growth and expansion of built-up structures. The results of the study reflect why immediate actions on the continuous urbanization is needed to prevent its negative impacts on Baguio's climate to which the city is known for.

\section{ACKNOWLEDGEMENTS}

The authors would like to acknowledge the Department of Science and Technology (DOST), and DOST Philippine Council for Industry, Energy, and Emerging Technology Research and Development (PCIEERD), Republic of the Philippines for funding and monitoring, respectively, the Project No. 4028, a nationwide research entitled Geospatial Assessment and Modelling of Urban Heat Islands in Philippine Cities (GUHeat).

\section{REFERENCES}

Bhatti S., Tripathi N., 2014. Built-up area extraction using Landsat 8 OLI imagery. GIScience and Remote Sensing, 51:4, 445 - 467. https://doi.org/10.1080/15481603.2014.939539.

Climate Engine, 2019. Climate Engine: cloud computing and visualization of climate and remote sensing data. Desert Research Institute and University of Idaho. climateengine.org

Deng Y., Wang S., Bai, X., Tian Y., Wu, L., Xiao, J., Chen, F., Qian, Q., 2018. Relationship among land surface temperature and LUCC, NDVI in typical karst area. Scientific Reports, 8 (1), 641, 2018.

Estoque, R.C., Murayama, Y., 2015. Classification and change detection of built-up lands from Landsat-7 ETM+ and Landsat8 OLI/TIRS imageries: A comparative assessment of various spectral indices. Ecol. Indic, 56, pp205-217.

Fernando, H. J. 2013. Handbook of Environmental Fluid Dynamics. 2. Pp143.

Gonzales, L. B., 2016. Urban sprawl: extent and environmental impact in Baguio City, Philippines. Spatium, 36, pp7-4.
Guha, S., Govil, H., Dey, A., Gill, N., 2018. Analytical study of land surface temperature with NDVI and NDBI using Landsat 8 OLI and TIRS data in Florence and Naples city, Italy. Eur. J. Remote Sens., 51:1, pp667-678.

Hirschi, M., Seneviratne, S.I., Alexandrov, V., Boberg, F., Boroneant, C., Christensen, O.B., Formayer, H., Orlowsky, B., Stepanek, P., 2010. Observational evidence for soil-moisture impact on hot extremes in southeastern Europe. Nat. Geosci., 4, pp17-21.

Jeevalakshmi, D., Narayana Reddy, S., Manikiam, B., 2017. Land Surface Temperature Retrieval from LANDSAT data using Emissivity Estimation. Int. J. Appl. Eng., 12 (20), pp.9679.

Landsberg, H.E. 1981. The Urban Climate, Academic Press, New York, p. 275

Lu D., Weng Q., 2009. Extraction of urban impervious surfaces from IKONOS imagery. Int. J. Remote Sens., 30, pp. 1297-1311

Malik, M. S., Shukla, J. P., Mishra, S., 2018. Relationship of LST, NDBI and NDVI using Landsat- 8 data in Kandaihimmat Watershed, Hoshangabad, India. Indian Journal of Geo Marine Sciences. 48, pp25-31.

McGranahan, G., Satterthwaite, D., 2014. Urbanisation concepts and trends. IIED Working Paper. IIED, London. http://pubs.iied.org/10709IIED

Morabito, M., Crisci, A., Messeri, A., Orlandini, S., Raschi, A., Maracchi, G., Munafò, M., 2016. The impact of built-up surfaces on land surface temperatures in Italian urban areas. Sci. Total Environ, 551-552.

Naserikia, M., Shamsabadi, E.A., Rafieian,M., Filho,W.L., 2019. The urban heat island in an urban context: a case study of Mashhad, Iran. Int. J. Environ. Res. Public Health, 16 (3), 313.

Navarro, A., 2004. Scrutinizing urbanization challenges in the Philippines through the infrastructure lens. PIDS discussion paper series no. 2014-2037.https://pidswebs.pids.gov.ph/CDN/ PUBLICATIONS/pidsdps1437.pdf. Accessed 02 August 2019.

PAGASA. www.pagasa.dost.gov.ph. Accessed June 2019.

Song, J., Du, S., Feng, X., \& Guo, L., 2014. The relationships between landscape compositions and land surface temperature: Quantifying their resolution sensitivity with spatial regression models. Landscape and Urban Planning, 123, 145-157.

Vautard, R., Yiou, P., Andre, F. D., De Noblet, N., Viovy, N., Cassou, C., Polcher, J., Ciais, P., Kageyama, M., Fan, T., 2007. Summertime European heat and drought waves induced by wintertime Mediterranean rainfall deficit, Geophys. Res. Lett., 34, doi:10.1029/2006GL028001.

Zhang, P., Sun, Q., Liu, M., Li, J., Sun, D., 2017. A strategy of rapid extraction of built-up area using multi-seasonal Landsat-8 thermal infrared band 10 images. Remote Sens, 9, 18p.

Zhang, Y., Guindon, B., 2012. Multispectral analysis for manmade surface extraction from RapidEye and SPOT5. Can. J. Remote. Sens., 38 (2012), pp180-196 